\title{
Big hitter in pulmonology
}

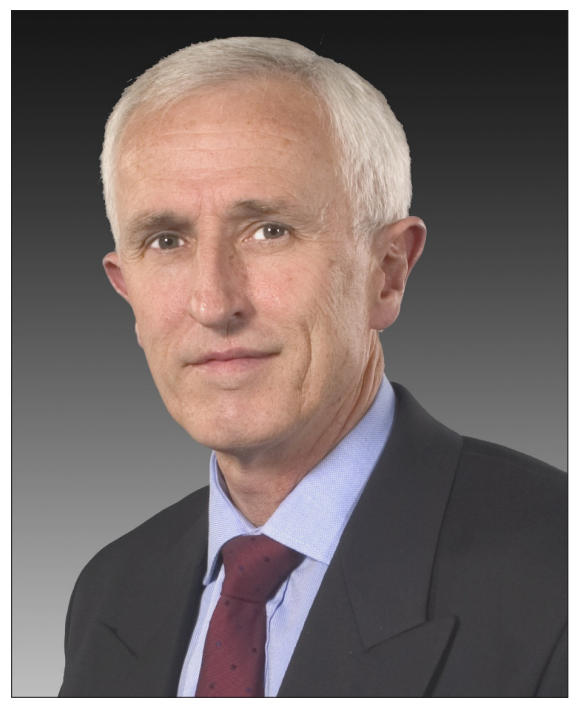

Eric Bateman: Distinguished clinician, scientist and marathoner

Eric Bateman, who is currently emeritus professor of medicine in the Knowledge Translation Unit at the University of Cape Town Lung Institute (UCTLI), has left a large footprint in the field of respiratory medicine in South Africa (SA) and globally. In his younger days, he was also well known as an elite marathoner. As a clinician scientist, he has published more than 300 articles in international medical journals, including several landmark papers on asthma management that have impacted international guidelines. These publications earned him the singular honour in 2018 of being named by the Web of Science Clarivate Analysis as one of the world's most highly cited researchers in any academic discipline for the years 2006 - 2016.

Prof. Bateman was born and schooled in Pretoria, but his medical studies, including specialisation in internal and respiratory medicine and a Doctor of Medicine degree, were completed at UCT. His training in respiratory medicine was first under the mentorship of Prof. Alex Ferguson, and then, for the majority of his career, he was privileged to have Prof. Solly Benatar as both a mentor and colleague. He was awarded the Diploma in Child Health and membership of the Royal College of Physicians in London in 1973 and 1974, respectively. In 1979 he returned to London as an ICI (SA)
Pharmaceutical Research Fellow, where he undertook full-time research at the Royal Postgraduate Medical School and Brompton Hospital, under the direction of Dame Margaret Turner-Warwick and Prof. Peter Cole. His doctorate was awarded by UCT in 1984 for a thesis entitled 'Fibrogenic mechanisms and sequence of collagen deposition in pulmonary fibrosis'. The work examined some of the critical mechanisms underlying the development of scarring of the lung caused by organic dusts such as asbestos and silica, and the types and patterns of collagen deposition in scar tissues in lung and in animal models. He was elected a Fellow of the Royal College of Physicians in 1986, and appointed head of the Respiratory Clinic at Groote Schuur Hospital (GSH), which he directed from 1989 to 2012. In 1996, he was promoted to Professor of Respiratory Medicine at the University of Cape Town, and in 1998 founded the UCTLI, serving as its director until December 2015. He remains in active research at the institute and travels extensively; to date, he has been an invited speaker in more than 60 countries!

Prof. Bateman describes his reason for choosing an academic career in SA as his appreciation of the enormous burden of disease, and the potential, as well as the responsibility, of the medical profession to address these needs using first-world science and technology. Hence, the motto of the UCTLI is broad: 'Addressing priority health issues through education, research and service. Over 20 years, the institute has served as an extended platform for the training of pulmonologists and researchers. Prof. Bateman reports that the greatest legacy and reward for his years of work is the generation of pulmonologists and health researchers that continue to serve in SA.

Prof. Bateman's primary research interests have been the pharmacology and management of asthma, chronic obstructive pulmonary disease and tuberculosis, as well as community-based interventions to improve the care of patients with chronic diseases. While his major clinical responsibilities included leadership of the clinical services in respiratory medicine, allergology and critical care at GSH, his desire grew over time to address the unacceptably high burden of asthma, including mortality from this highly treatable disease. His first landmark paper, the GOAL study (published in 2004) was the first large-scale trial that examined the extent to which symptoms of asthma could be completely controlled, enabling patients to live a normal life. As a result of this study, the focus of asthma treatment (and primary endpoint in clinical trials) became the achievement of complete symptom control, an approach also adopted in global and national guidelines. Another example of his research that broke new ground in asthma care was the SYGMA study in mild asthma published in 2018. With the establishment of the UCTLI, he and his team, later to become the Knowledge Translation Unit (KTU), went on to develop an approach called the Practical Approach to Care Kit (PACK), designed to improve the care of patients attending primary care clinics in $\mathrm{SA}$, and in state-run facilities in other lowmiddle income countries. This programme has led to the founding of an international PACK movement that seeks to lobby for and improve universal access to quality primary healthcare. The KTU has assisted in the establishment of PACK programmes in Botswana, Brazil, Nigeria, Ethiopia and Malawi, and an SA version forms part of the primary care approach throughout SA.

Among his many honours and distinctions are an A-rating from the National Research Foundation of SA, and Life Fellowship of UCT and the South African Thoracic Society, which he served as president for three terms. $\mathrm{He}$ is also a founding Fellow of the European Respiratory Society, a board member of the Burden of Obstructive Lung Disease Initiative and was a founding member of the Executive of the World Health Organization's Global Alliance Against Chronic Respiratory Diseases (GARD). He has served on the board and science committee of the Global Initiative for Asthma (GINA) for more than 15 years, and served as chairman of the board for 3 years.

Prof. Bateman has been the recipient of several prestigious awards and honours, including: the Alan Pifer Award from UCT in 2012, in recognition of outstanding 
welfare-related research; the President's Award from the European Thoracic Society in 2012, in recognition of global contribution to Respiratory Medicine; the SA Medical Research Council Lifetime Achievement Award (Platinum) in 2013; the National Science and Technology Forum-BHP Billiton Lifetime Award for Outstanding Contribution to Science, Engineering, Technology and Innovation in 2014; a Fellowship in the Art and Science of Medicine from the South African Medical Association in 2014; and the World Lung Health Award from the American Thoracic Society in 2018 'for contribution to improving world lung health through translational or implementation research, delivery of healthcare, continuing education and care of patients with lung disease, and political advocacy. At various times, Prof. Bateman has served on editorial or advisory boards of many international journals, including Thorax, the European Respiratory Journal, the Journal of Allergy and Clinical Immunology, Therapeutic Advances in Respiratory Disease, BioMed Central: Pulmonary Medicine, COPD: Journal of the COPD Foundation, the South African Respiratory Journal (now the African Journal of Thoracic and Critical Care Medicine) and the Primary Care Respiratory Journal.

Prof. Bateman is also well-known for his long and successful career in road running. A founder and honorary life member of the VOB Running Club in Cape Town, he has been a gold medalist in both the Comrades
Marathon (in 1984) and in the $56 \mathrm{~km}$ Two Oceans Marathon, on two occasions, is a past South African Marathon Champion (42 km) in the veteran category, and at the height of his running career, was one of three nominees

\section{Career advice pearls}

What advice does Prof. Bateman offer to young pulmonologists and scientists?

- Seek role models. Look for and emulate colleagues that you admire for their example in different aspects of medicine: astute clinician, caring therapist, rigorous scientist, compassionate philanthropist.

- Select your field(s) of special interest. This should preferably be determined by need and opportunity, relevance in your practice environment and what you are best positioned to study. Remember that 'one in the hand is worth two in the bush.' Address the needs around you.

- Ask big questions. What are the big issues demanding attention? There is no limit to the number of topics in medicine that can be studied, but not all are worthy of study and will lead to a lifetime of deepening interest and sustainable research.

- Build research collaborations with trusted friends. Most big questions need to be addressed by large teams with complementary expertise and resources. Focus on building friendships first, then partnerships, especially with overseas researchers. The age of lone researchers is long past.

- Walk, don't run. With the extreme demands on clinician scientists in South Africa to run clinical services, mentor and train and perform research, it is easy to become discouraged. Good research is often based on good clinical observation and experience gained in practice. In Prof. Bateman's case it was many years before he had gained the stature, status and opportunity to ramp up his research to its current levels. Good measures of patience, persistence and optimism are called for, but the rewards are great and worth working toward. A career as a clinician scientist is a marathon rather than a sprint. 